\title{
A Review of Cattail (Typha) Invasion in North American Wetlands
}

\section{Overview}

Cattail (Typha) is an iconic emergent wetland plant found worldwide. By producing an abundance of winddispersed seeds, cattail can colonize wetlands across great distances, and its rapid growth rate, large size, and aggressive expansion result in dense stands in a variety of aquatic ecosystems such as marshes, ponds, lakes, and riparian areas. Cattail can also quickly dominate disturbed areas with waterlogged soils such as roadside ditches, retention areas, and fringes of stormwater ponds. These dense stands impact local plant and animal life, biogeochemical cycling, and wetland hydrology, which in turn alter wetland functions. Over recent decades, the distribution and abundance of cattail in North America has increased as a result of human disturbances to natural water cycles and increased nutrient loads. In addition, highly competitive nonnative and hybrid taxa have worsened the rapid spread of cattail.

Because cattail invasion and expansion often change wetlands in undesirable ways, wetland managers often respond with widespread management efforts, though these efforts may have short-lived or weak effects. Notwithstanding the negative impacts, cattail provides beneficial ecosystem services including the reduction of pollution through bioremediation and the production of biofuel material.

Despite the widespread distribution and invasive characteristics of cattail, a comprehensive review and synthesis of past and current research on cattail was lacking. To address this gap, a diverse team of researchers produced a paper that details the spread and management of cattail throughout North America, summarizing 4 decades of research from more than 650 references (Bansal and others, 2019). This fact sheet highlights the primary topics covered in the paper.

\section{Biology and Ecology of Cattail}

Cattail is an herbaceous, perennial plant found in aquatic ecosystems. Broadleaf cattail (T. latifolia L.), narrowleaf cattail (T. angustifolia L.), southern cattail (T. domingensis Persoon), and an invasive hybrid of broadleaf and narrowleaf cattail ( $T$. $\times$ glauca Godr.) are found throughout North America. Broadleaf cattail and southern cattail are native to North America, whereas narrowleaf cattail likely has European origins. The hybrid cattail is especially invasive owing to hybrid vigor, where it benefits from traits of both parental species.

All cattail species have numerous traits that allow them to spread and thrive in disturbed environments, where they often form dense stands (fig. 1). In late summer, cattail releases as many as 700,000 wind-dispersed seeds per flower that can travel more than 0.6 mile ( $\sim 1$ kilometer) to colonize distant aquatic habitats. After colonization, cattail grows quickly, becomes quite large (taller than 6 feet [ 2 meters]), and spreads rapidly.

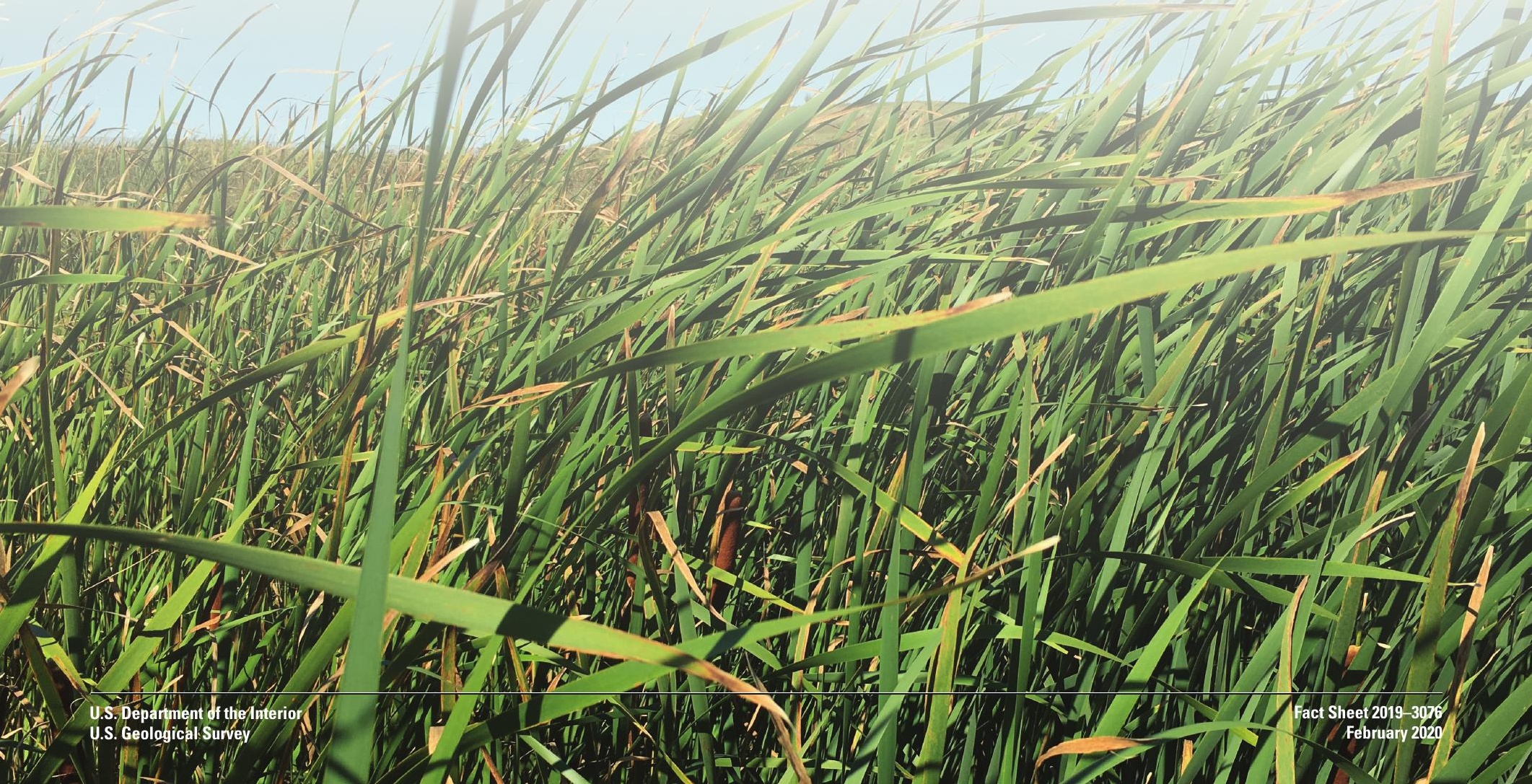




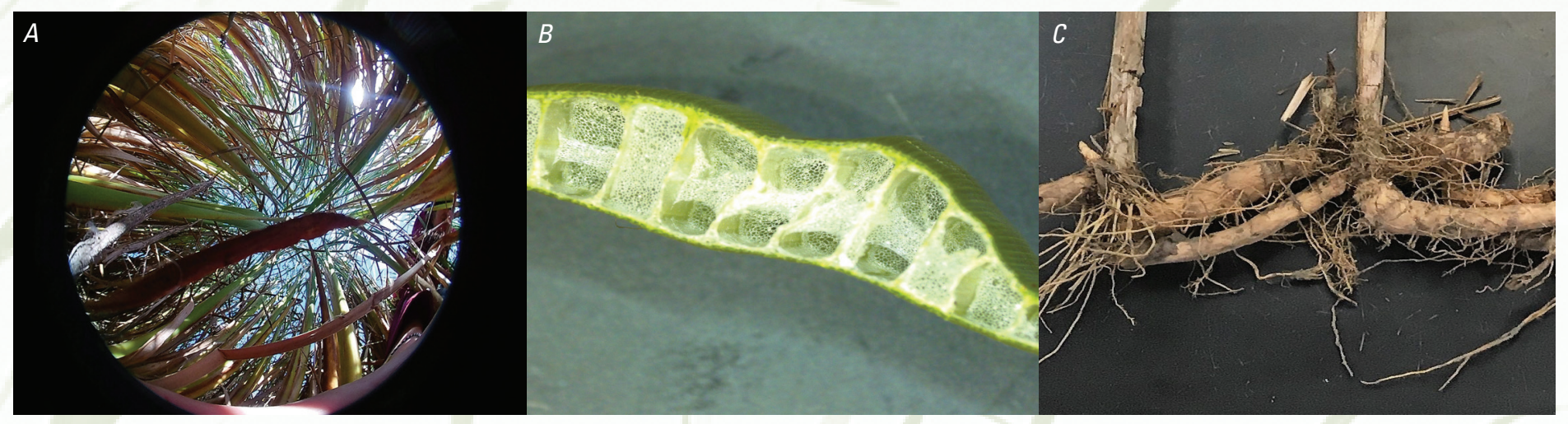

Figure 1. Cattail has a number of adaptive traits that allow it to grow and thrive in wetland environments. $(A)$ Dense stands of cattail reduce growth of competing vegetation. The image is a hemispherical photograph from the point of view of an emerging seedling in a cattail stand. $(B)$ A cattail leaf cross-section shows aerenchyma (that is, an air-ventilation system), which allows cattail to transport oxygen to its roots efficiently. $(C)$ Rhizomes and roots of cattail; rhizomes allow cattail to reproduce from a single plant and to store carbohydrates and nutrients for regrowth in the spring. Photographs by $(A, B)$ Olivia Johnson, U.S. Geological Survey, and (C) Jacob Meir, U.S. Geological Survey.

Cattail thrives in flooded environments owing to the plant's air-ventilation system, which transports oxygen to the rhizomes (that is, root system). Rhizomes also store carbohydrates and nutrients during the winter, allowing for rapid springtime growth.

\section{Ecological, Agricultural, and Biogeochemical Impacts of Cattail Invasion}

The invasion of aquatic ecosystems by cattail affects many aspects of wetland ecology and function (fig. 2).
Displacement of diverse plant communities by dense cattail stands decreases plant diversity; reduces or eliminates forage-producing plants favored by water birds, wildlife, and pollinators; alters the physical structure of the plant community; and increases plant litter. Changes

\section{Causes of Invasion-Regional Case Studies}

Although cattail has many traits that allow it to thrive in wetlands, it also has limitations that typically keep populations in check. Specifically, cattail requires saturated or flooded soils with less than 6 feet ( 2 meters) of water. Thus, cattail growth is inhibited when water levels rise or fall for sufficiently long periods of time (more than 2 years). Cattail is also less efficient at nutrient uptake under oligotrophic (that is, low nutrient) conditions, and therefore may be outcompeted by native vegetation. However, long-term alteration of natural hydrologic regimes combined with increased nutrient loads from agricultural runoff has created conditions that are favorable to cattail, leading to dramatic increases in cattail abundances. Bansal and others (2019) highlighted three regions that have experienced extensive invasion by various species of cattail as a result of nutrient enrichment and hydrologic alterations: the Laurentian Great Lakes, the Prairie Pothole region, and the Florida Everglades.
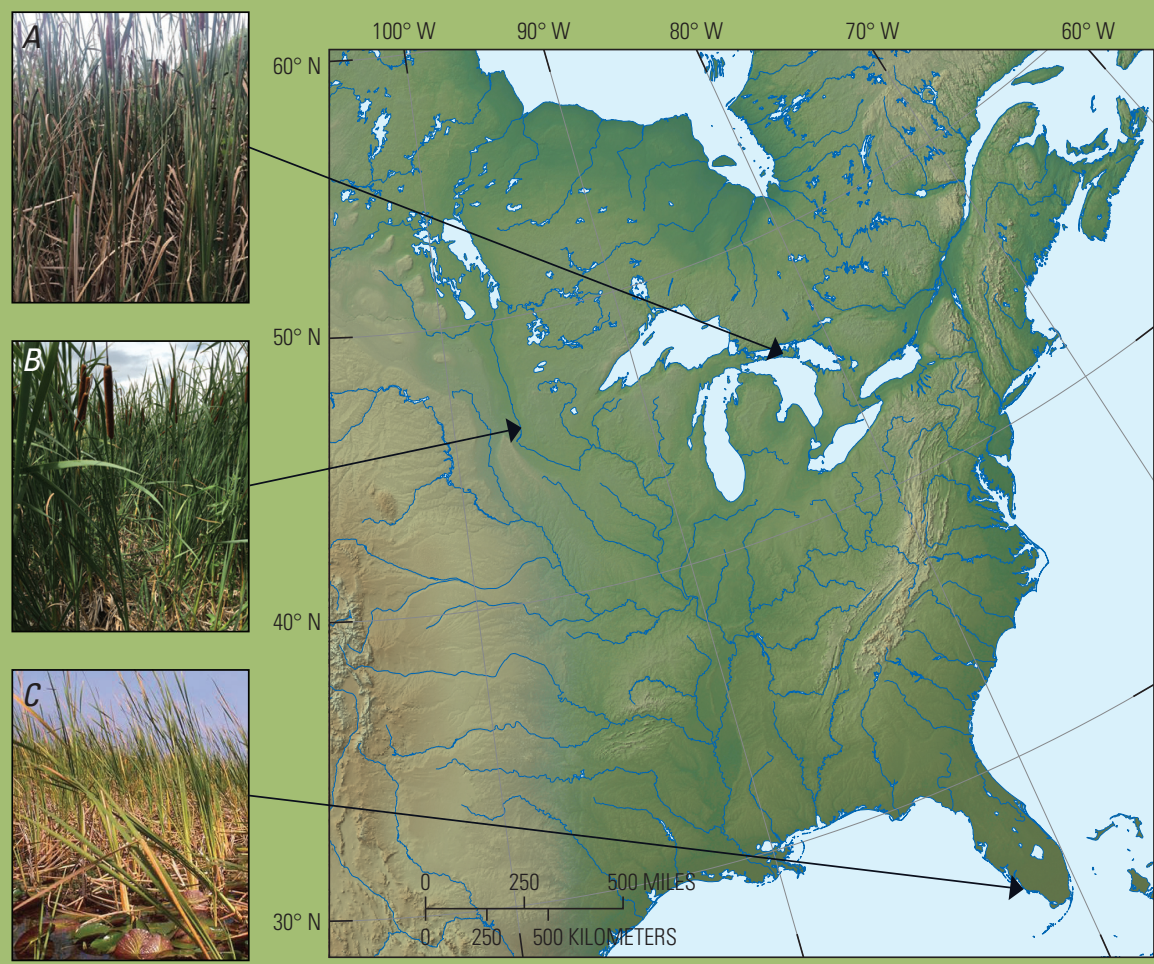

Cattail invasion has been particularly aggressive in North America, in part due to nutrient enrichment from agricultural runoff and altered hydrologic regimes. Three regions that have experienced significant invasion by cattail include $(A)$ the Laurentian Great Lakes region, $(B)$ the midwestern Prairie Pothole region, and $(C)$ the Florida Everglades. Photographs by $(A)$ Shane Lishawa, Loyola University Chicago; $(B)$ Sheel Bansal, U.S. Geological Survey; $(C)$ Sue Newman, South Florida Water Management District. Physical map of North America from Natural Earth (naturalearthdata.com). 
in plant diversity and structure reduce habitat complexity preferred by many water birds for breeding and can negatively affect invertebrate and fish populations, which are critical food sources for a variety of wildlife. Cattail invasion may also encourage faster drying of wetlands and habitat fragmentation, which can negatively impact populations of wetland-dependent wildlife such as amphibians. Additionally, cattail invasion has a wide variety of negative effects on agricultural production; it can compete with water-submerged crops such as rice, obstruct irrigation canals and drainage ditches, and provide roosting habitat for flocks of birds (for example, blackbirds), which can cause extensive damage to crops such as sunflower.

Cattail invasion enhances nitrogen and phosphorus cycling in wetlands due to increased dead plant material and nutrient-rich sediment. Much higher concentrations of extractable nitrate, ammonium, and phosphate are commonly found in soils of cattail patches in invaded marshes. Cattail-dominated sites also store large amounts of carbon as soil organic matter, which provides a climate benefit. However, cattail increases wetland methane (a powerful greenhouse gas) emissions by providing carbon to fuel methane-producing microbes and by providing a conduit for methane release through the rhizomes and stems.

\section{Ecosystem Services}

Even though cattail is considered an invasive plant in many ecosystems, it also provides many beneficial ecosystem services. For example, a variety of
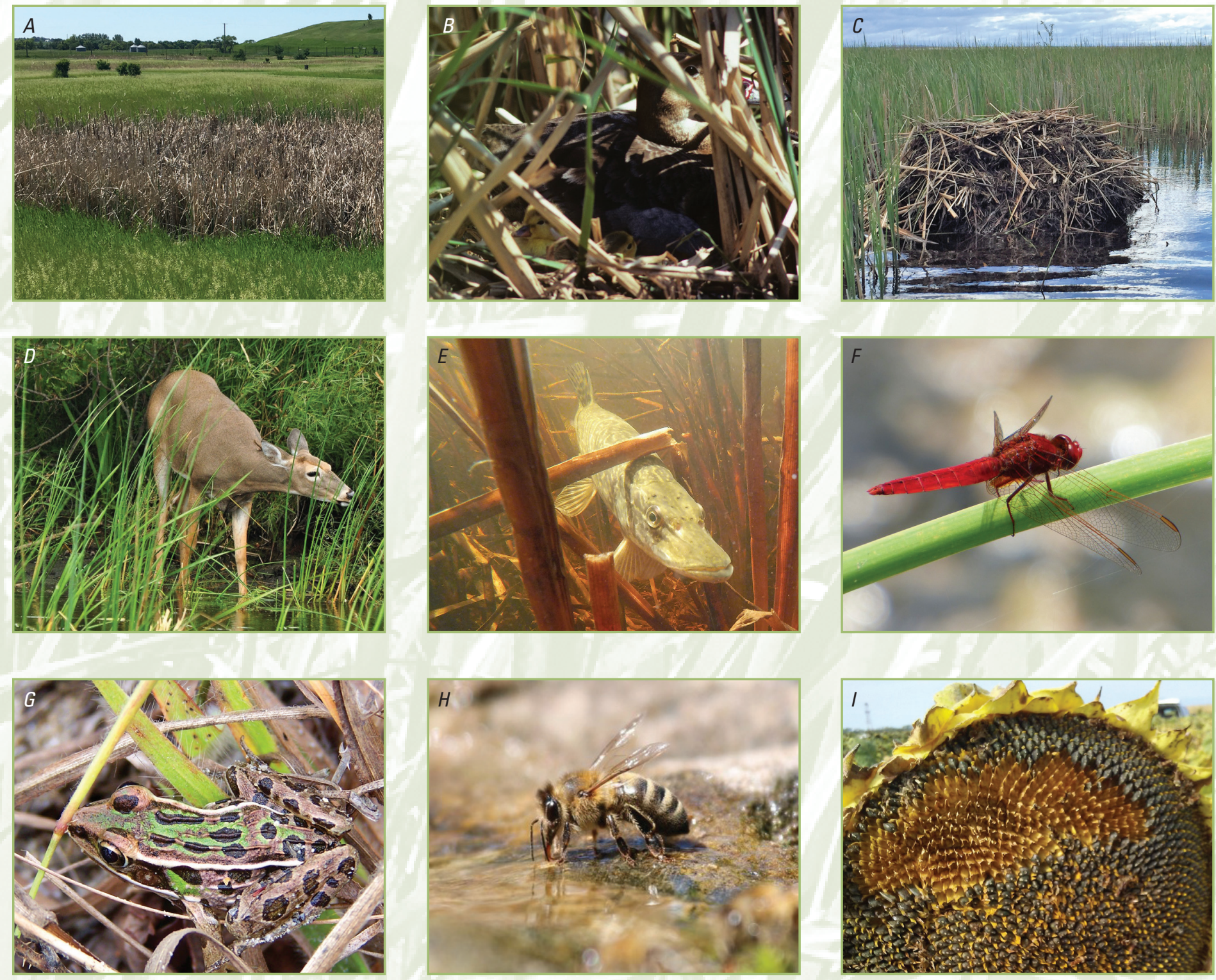

Figure 2. Cattail invasion affects nearly all plant and animal communities in and around wetland ecosystems including $(A)$ native vegetation, $(B)$ water bird breeding habitat, $(C)$ muskrat den-building material, $(D)$ deer cover, $(E)$ fish spawning habitat, $(F)$ invertebrate habitat, $(G)$ amphibian habitat, $(H)$ pollinator habitat, and $(I)$ surrounding agriculture. Photographs by $(A)$ Sheel Bansal, U.S. Geological Survey (USGS); $(B)$ Michael Anteau, (USGS); (C) Amy Shrank, University of Minnesota; (D) Lowell Washburn, lowa Department of Natural Resources; (E) Craig Bihrle, North Dakota Game and Fish Department; (F) pixabay.com; (G) Ai Wen, University of Northern lowa; $(H)$ pixabay.com; (I) Page Klug, U.S. Department of Agriculture. 

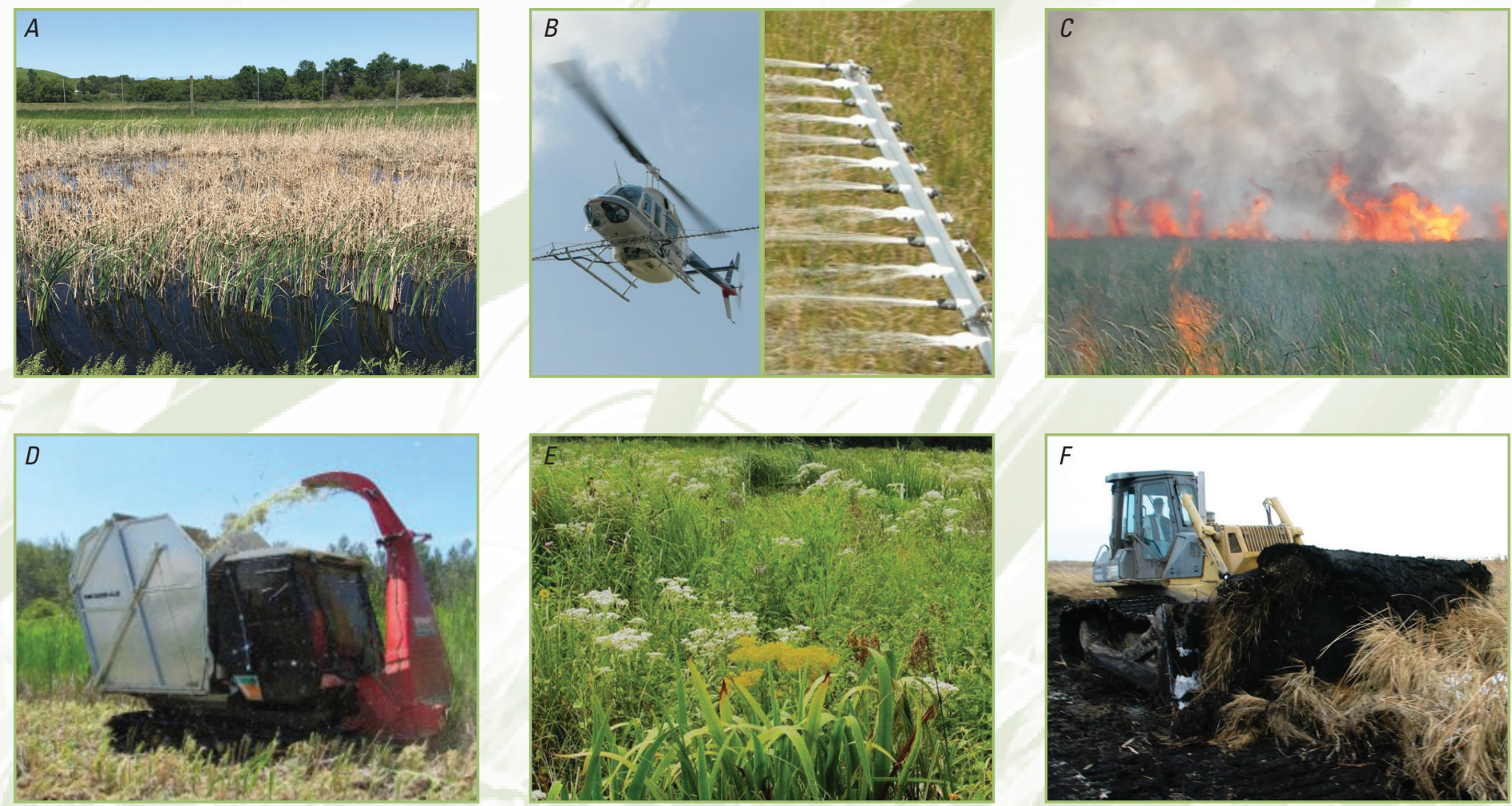

Figure 3. Examples of cattail management techniques. (A) Water-level manipulation (flooding) in an experimental wetland at the U.S. Geological Survey, Northern Prairie Wildlife Research Center in the North Dakota Prairie Pothole region; $(B)$ aerial application of herbicide to manage cattail within the northern Everglades; $(C)$ planned burn of a cattail marsh at Agassiz National Wildlife Refuge, Minnesota; $(D)$ harvesting cattail with a biomass harvester designed for wetland use in Cheboygan Marsh, Michigan; $(E)$ revegetation to restore plant diversity at Cowles Bog Wetland Complex in Indiana Dunes National Lakeshore; and ( $F$ removal of cattail biomass and sediment to restore wetland habitat in the Prairie Pothole region. Photographs provided by $(A)$ Sheel Bansal, U.S. Geological Survey; $(B)$ Scot Hagerthey, U.S. Environmental Protection Agency; (C) Larry Anderson, U.S. Fish and Wildlife Service (FWS); (D) Shane Lishawa, Loyola University Chicago; ( $E$ ) Joy Marburger, National Park Service; (F) Mark Fisher, FWS.

indigenous peoples use parts of the cattail plant for a range of products including food, medicine, and goods such as woven baskets or mats. It also provides forage and shelter to certain animals, such as for building muskrat dens.

Cattail is also useful for wetland bioremediation, where it breaks down and removes waterborne contaminants. Cattail removes metals and nutrients through its rapid growth rates, ability to extract elements from the soil, tolerance of contaminated environments, and the limited movement of harmful elements from its roots to aboveground biomass. Cattail can be harvested to further remove nutrients and contaminants from the environment. Cattail can also be used for energy production (for example, biofuels or compressed fuel pellets), as well as for compost and livestock bedding, agricultural soil enhancement, and carbon sequestration.

\section{Management}

Control and removal of cattail has long been a management goal in aquatic ecosystems. Control measures include herbicide treatments, burning, flooding, mowing, crushing, revegetation, and grazing (fig. 3). Despite decades of research, effective long-term control is still a challenge to achieve and the effects of successful treatments often are short-lived. For example, mechanical (mowing) or chemical (herbicide) control techniques are seldom effective because extensive rhizome systems support rapid regeneration of cattail stands. Regardless of the management technique employed, multiple actions are typically needed to control cattail, and the stage in the plant life cycle in relation to time of year should be considered to achieve maximum effectiveness. Management trade-offs, including impacts on desired plant and animal species, must also be considered when managing cattail.

\section{Research Needs}

Although there is an extensive collection of research and management articles focused on cattail, major information gaps remain. Little research has been dedicated to understanding and predicting the future distribution of cattail (especially hybrid cattail) in response to climatic changes, in addition to humancaused changes to nutrient loads and hydrologic regimes of wetlands. Better knowledge of cattail genetics and where cattail has existed in the distant past (through paleoecological records) will help scientists understand the key factors associated with invasion.

Investigations into the ecological impacts of cattail invasion have focused primarily on changes in plant and bird communities. Future research should also include more detailed studies that examine the effects of cattail invasion on fish, invertebrates, amphibians, and pollinators. In addition, research is needed to 


\section{Case Study-Ecosystem Services Biofuels/Biomass Harvest}

Reducing and removing cattail biomass is often a primary goal of wetland management. Cattail has been identified as a potential biofuel crop and a source for bioenergy products such as compressed fuel pellets. Moreover, the use of cattail biomass instead of traditional agricultural sources (such as corn) has numerous advantages including
(1) cattail grows in aquatic habitats and does not require the use of conventional agricultural land, (2) it has a rapid growth rate, (3) it is not a net source of carbon to the atmosphere, (4) it typically does not require active management (for example, tillage or planting), and (5) harvest generally improves wetland habitats and removes excessive nutrients from aquatic systems. Studies conducted at Netley-Libau Marsh and Pelly's Lake in the Lake Winnipeg watershed, Canada, showed how cattail biomass harvest resulted in the removal of considerable amounts of nitrogen and phosphorus from the Red River, which flows into Lake Winnipeg, and the restoration of wetland habitat. This research guided large-scale application of management practices to remove phosphorus. As an additional benefit, use of cattail biomass as fuel reduces the need for coal.

Cattail biomass harvested for fuel. Photograph by Richard

Grosshans, International Institute for Sustainable Development.

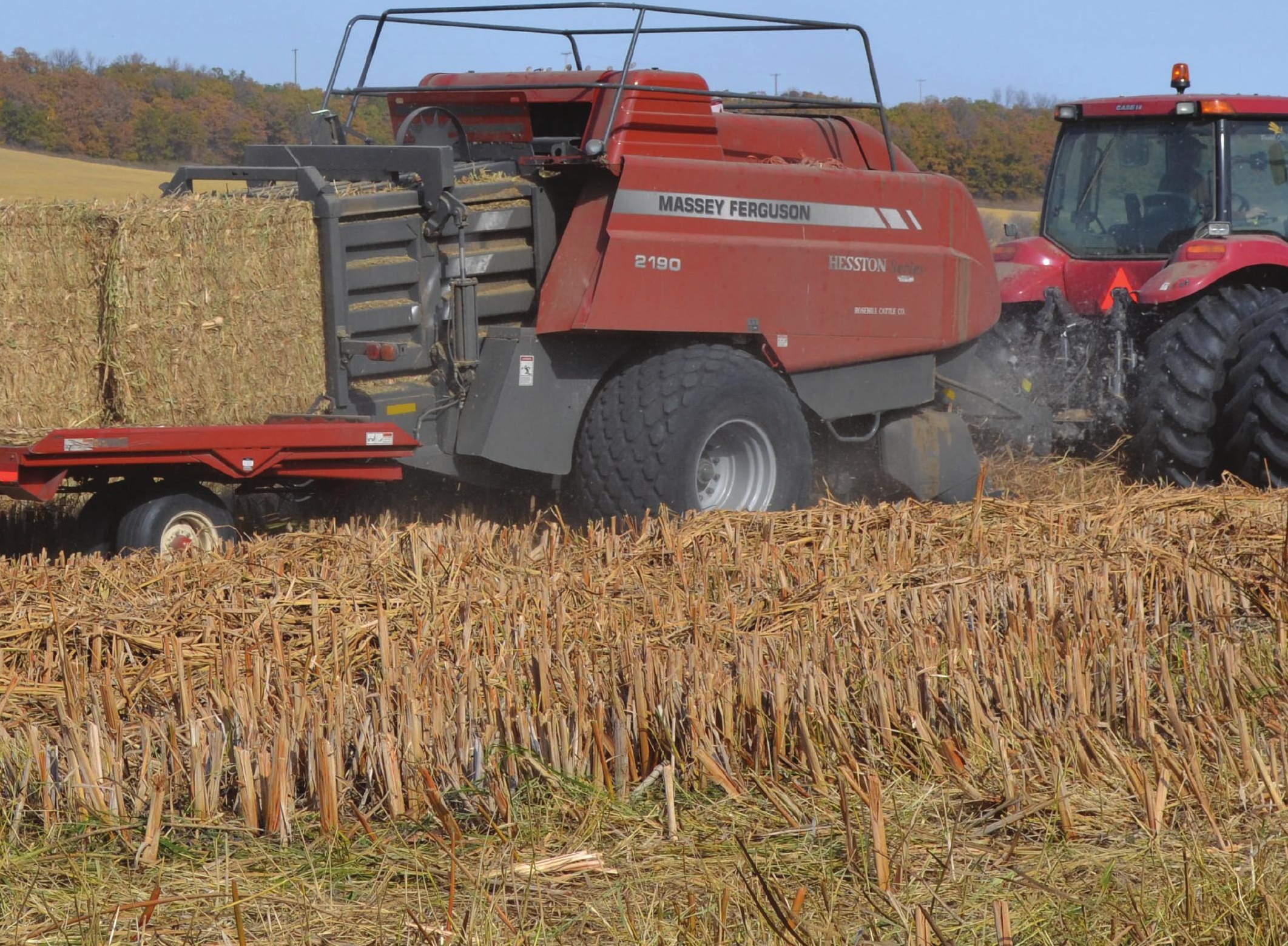


clarify relations between cattail invasion and nitrogen, phosphorus, and carbon cycling. Future studies should examine how to reverse the positive feedback loop between altered hydrology, nutrient availability, and cattail invasion.

Along with continued research on cattail control methods, information is needed to address questions such as, "when does cattail invasion necessitate management and control efforts?" and "do the benefits of cattail control outweigh potential negative impacts downstream?" Regardless of the research focus, studies should be conducted in a variety of diverse regions and habitats, be performed at management-relevant scales, and be of appropriate length to assess long-term outcomes.

\section{Reference}

Bansal, S., Lishawa, S.C., Newman, S., Tangen, B.A., Wilcox, D., Albert, D., Anteau, M.J., Chimney, M.J., Cressey, R.L., DeKeyser, E., Elgersma, K.J., Finkelstein, S.A., Freeland, J., Grosshans, R., Klug, P.E., Larkin, D.J., Lawrence, B.A., Linz, G., Marburger, J., Noe, G., Otto, C., Reo, N., Richards, J., Richardson, C., Rodgers, L., Schrank, A.J., Svedarsky, D., Travis, S., Tuchman, N., and Windham-Myers, L., 2019, Typha (cattail) invasion in North American wetlands-Biology, regional problems, impacts, ecosystem services, and management: Wetlands, v. 39 , no. 4 , p. 645-684. [Also available at https://doi.org/10.1007/s13157019-01174-7.]

\section{Case Study-Cattail, Blackbirds, and Crop Damage in the Prairie Pothole Region}

In the Prairie Pothole region of North America, various species of blackbirds cause considerable economic damage to crops such as sunflower and corn. The extremely large populations of these birds favor cattail-dominated wetlands as roost sites because the dense stands provide protective cover. Flocks proceed from these wetlands to forage in nearby crops, with recent (2010) damage estimates of nearly \$4 million in North Dakota alone. Reducing the areal coverage of cattail habitat is one method of dispersing large blackbird concentrations to many smaller roosts, thereby reducing the severity of localized crop damage while improving wetland habitat.

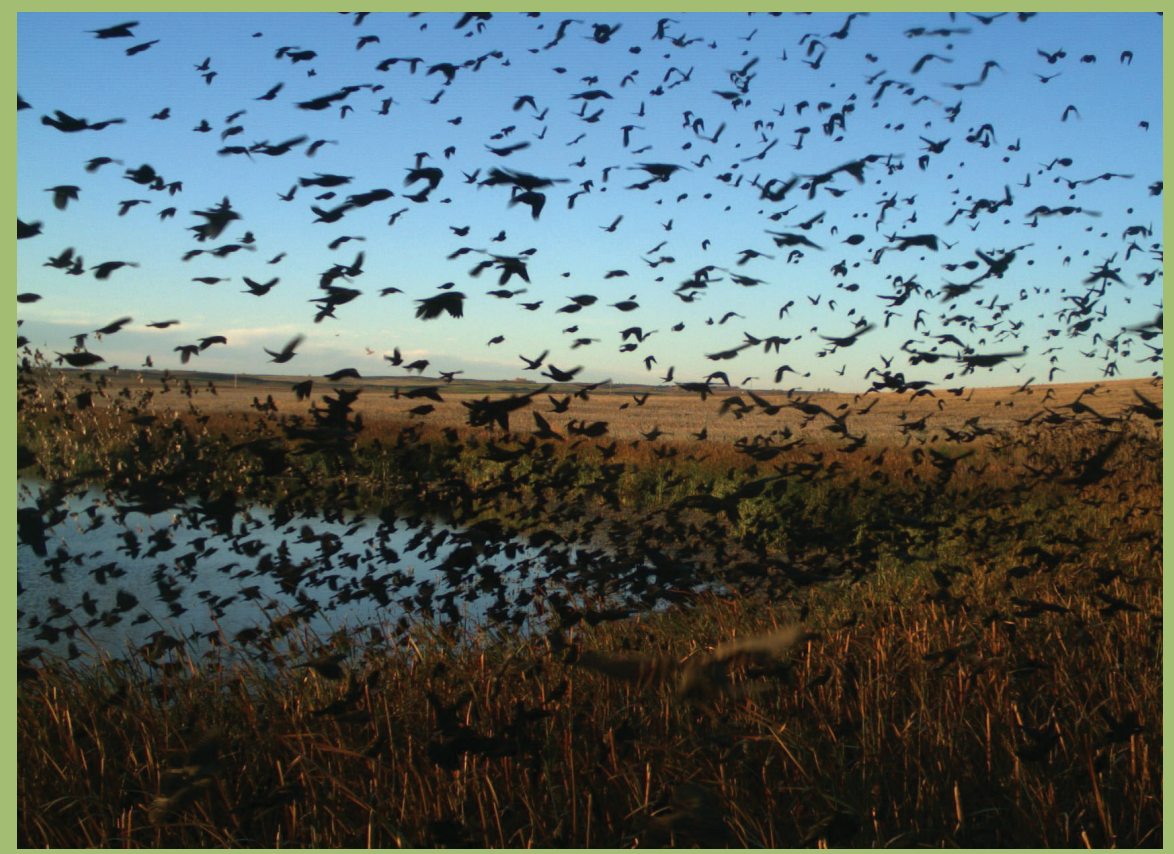

Blackbird (/cteridae) flock roosting in cattail. Three blackbird species, red-winged blackbirds (shown in figure), common grackles, and yellow-headed blackbirds cause significant economic damage to crops such as sunflower and corn. Photograph by Page Klug, U.S. Department of Agriculture.

\section{Additional Information}

For additional information concerning this publication, contact:

Director, USGS Northern Prairie Wildlife Research Center 8711 37th St. SE Jamestown, ND 58401 (701) 253-5500
Or visit the Northern Prairie Wildlife Research Center website at https://www.usgs.gov/centers/npwrc.

\section{By Sheel Bansal (U.S. Geologi-} cal Survey), Brian Tangen (U.S. Geological Survey), Shane Lishawa (Loyola University Chicago), Sue Newman (South Florida Water Management District), and Douglas Wilcox (SUNY College at Brockport)
Background photograph by Sheel Bansal.

Publishing support provided by the West Trenton Publishing Service Center.

ISSN 2327-6916 (print) ISSN 2327-6932 (online) https://doi.org/10.3133/fs20193076 